\title{
Technological aspects regarding machining the titanium alloys by means of incremental forming
}

\author{
Octavian Bologa ${ }^{1, *}$, and Carmen Cotigă ${ }^{1}$ \\ ${ }^{1}$ Lucian Blaga University of Sibiu, Department of Industrial Machines and Equipment, 550025 \\ Victoriei 10, Sibiu, Romania
}

\begin{abstract}
Titanium alloys are materials with reduced formability, due to their low plasticity. However, today there are high demands regarding their use in the automotive industry and in bio-medical industry, for prosthetic devices. This paper presents some technological aspects regarding the machinability of titanium alloys by means of incremental forming. The research presented in this paper aimed to demonstrate that the parts made from these materials could be machined at room temperature, in certain technological conditions.
\end{abstract}

\section{Introduction}

Lightweight materials are demanded nowadays mostly in the automotive industry. However, titanium alloys, due to their biocompatibility are also suitable for use in biomedical industry, for manufacturing prosthetic devices [1-2]. Because prosthetic devices are prototypes, being tailored for each patient, incremental forming is one of the machining processes which could be used for manufacturing them. However, titanium alloys are well known for their low-plasticity and processing them by plastic deformation could be a problem. Also, parts machined by incremental forming are subject to dimensional errors.

To overcome these aspects, in [3] is presented an approach which uses high speed forming reducing the geometrical errors of the parts machined by incremental forming. Heating the parts by different methods is also a method reported in the literature as a way for increasing the plasticity of the titanium alloys during machining them by plastic deformation. In [4], the heating is achieved combining local heating with the heat generated by friction due high tool speed. The research presented in [5] is based upon heating the parts using direct current. Paper [6] also presents some promising results regarding the incremental forming of parts heated by means of electrical methods. However, the process of heating the parts has also some significant drawbacks: the temperature is very difficult to be controlled and heating could lead to oxidation, which can dramatically affect the biocompatibility of the titanium alloys.

The approach presented in this paper is to machine the parts made form Ti6Al4V titanium alloy, by means of incremental forming at room temperature, in order not to affect their biocompatibility.

\footnotetext{
* Corresponding author: octavian.bologa@ulbsibiu.ro
} 


\section{The experimental layout and the processed parts}

Incremental forming involves the coordinated control of the processed sheet workpiece in $\mathrm{XY}$ plane, while the tool (punch) is moving incrementally on $\mathrm{Z}$ axes. Consequently, CNC milling machine are suited to be used as technological equipment for this process.

For processing parts by means of incremental forming, a CNC milling machine Haas MiniMill 1 was used. A CAD/CAM approach was used for generating the $\mathrm{NC}$ code for driving the punch on the processing toolpaths, due to the closeness between a milling process using a spherical mill and an incremental forming process using a punch with a hemispherical head.

The experimental layout is presented in figure 1. This experimental layout was successfully used before by the authors for some other incremental forming machining processes [7-8].
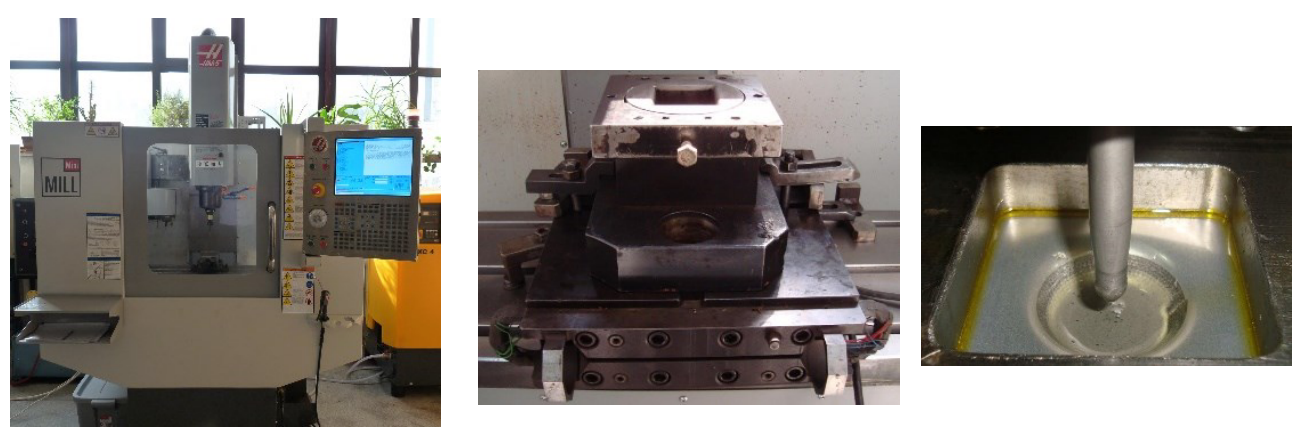

Fig. 1. Experimental layout: machine, fixture and processed part

The approach targeted the process of manufacturing prosthetic devices, mainly cranial prostheses. The slope angles for these kinds of parts are limited, so the initial assumption made by the authors was that the low plasticity of Ti6Al4V titanium alloy will not hinder the machining process at room temperature.

As test shape, the cone-frustum was selected to test if incremental forming could be performed on the parts, at room temperature without the occurrence of cracks. The starting slope angle of the cone-frustum parts was chosen $30^{\circ}$ and it was gradually increased.

Figure $2 \mathrm{a}$ shows the imposed geometry of a processed parts (side view), while figure $2 \mathrm{~b}$ shows the 3D model which was used for generating the CNC code for machining the part.

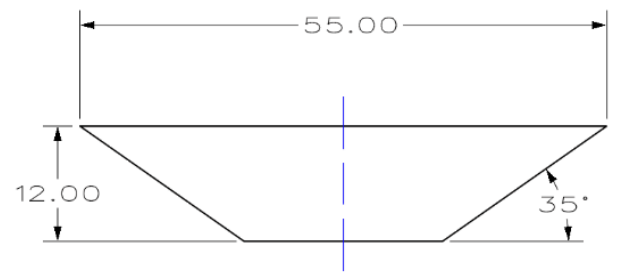

a.

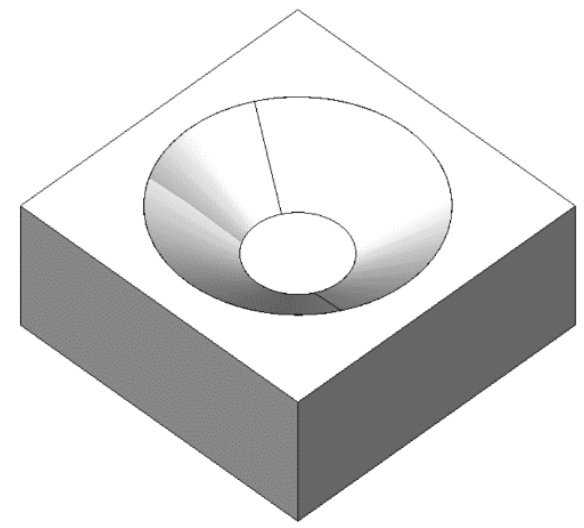

b.

Fig. 2. Example of processed part, side view (a) and 3D model (b) 


\section{The processing strategies and toolpaths}

To process the parts by means of incremental forming at room temperature, several technological conditions were selected. Preliminary researches have demonstrated that while the slope angle exceeds $30^{\circ}$, the vertical increment should be chosen in the range of 0.2-0.6 millimeters. Bigger vertical increments leaded to crack occurrence to more than $50 \%$ of machined parts.

Three types of toolpaths were considered: circular toolpaths, the tool was drive along one simple circular trajectory on every XY plane, each plane being situated at one vertical increment form each other (figure 3a). The second approach used Archimedes' spiral in each plane situated at one vertical increment from each other (fig. 3b). Finally, the third approach used a continuous spatial spiral toolpath for machining the whole part (fig. 3c)

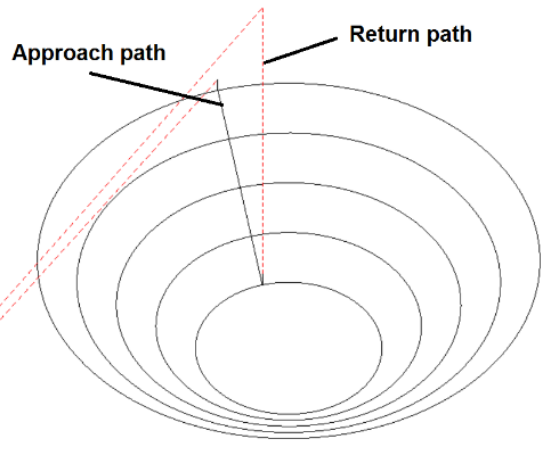

a.

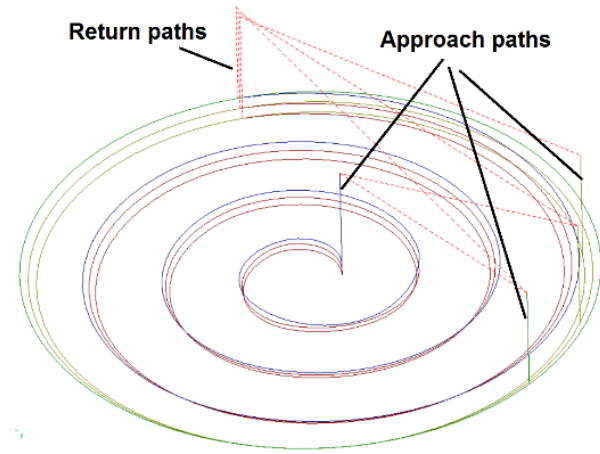

b.

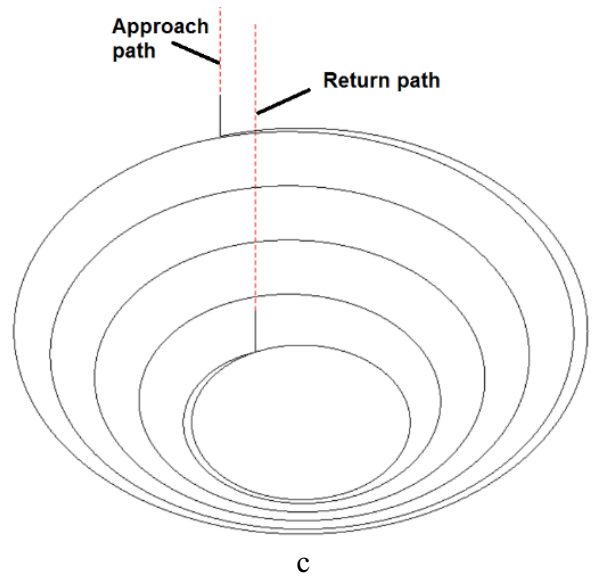

Fig. 3. Processing toolpaths, circles (a), Archimedes spiral (b), spatial spiral (c)

Table 1 presents a synthesis with regard of the results. It can be noticed the fact that the best results have been obtained by using the spatial spiral toolpath. This fact could be explained by observing that for this toolpath, there is only one entry point and one exit point, while between them the toolpath is continuous. For the other two approaches, there are multiple entry and exit points Entry points are considered stress concentrators for the incremental forming process and aligning them on a line as in figure $3 \mathrm{a}$ favors the apparition of cracking lines. Archimedes spiral toolpaths have shown slightly better results as simple circles, however the complexity of generating them is not compensated by this 
results. Archimedes spirals are not standardized toolpaths in most of the CAM programs, so the toolpaths had to be generated in a semi-automatic way.

From table 1 it can also be seen that the cracks started to occur at the angle of $37^{\circ}$ for circular toolpaths and a vertical increment of 0.6 millimeters and at $38^{\circ}$ for vertical increments of 0.4 millimeters. At a slope angle of $38^{\circ}$ and 0.6 vertical increment, the parts cracked every time, while for same conditions but Archimedes spirals the crack only occurred from some of the parts.

Finally, at slope angles bigger than $38^{\circ}$, the cracks occurred for every toolpaths and increment step. It was considered that this slope angle is the physical limit of machining parts from this material (Ti6Al4V titanium alloy), at room temperature, without heating the part by means of incremental forming.

In figure $4 \mathrm{a}$ a processed part is presented (with a slope angle of $35^{\circ}$, while in figure $4 \mathrm{~b}$ a processed part with cracks is shown (with a slope angle of $38^{\circ}$ ).

At this stage of the research the rotational speed of the tool was chosen $150 \mathrm{rev} / \mathrm{min}$ and the feedrate $150 \mathrm{~mm} / \mathrm{min}$, for all processed parts.

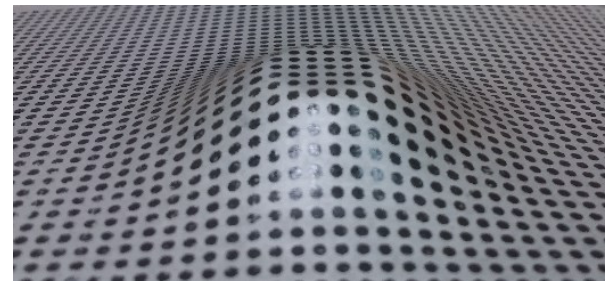

a.

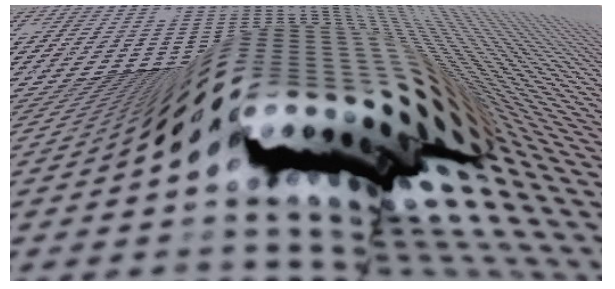

b.

Fig. 4. Processed part (a), processed part with cracks (b)

Table 1. Comparison

\begin{tabular}{|c|c|c|c|c|}
\hline $\begin{array}{l}\text { Slope } \\
\text { angle }\end{array}$ & $\begin{array}{l}\text { Increment } \\
\text { step }\end{array}$ & \multicolumn{3}{|c|}{ Trajectory } \\
\hline \multirow{3}{*}{$35^{\circ}$} & 0.2 & Circles & Archimedes spiral & Spatial spiral \\
\hline & 0.4 & Circles & Archimedes spiral & Spatial spiral \\
\hline & 0.6 & Circles & Archimedes spiral & Spatial spiral \\
\hline \multirow{3}{*}{$36^{\circ}$} & 0.2 & Circles & Archimedes spiral & Spatial spiral \\
\hline & 0.4 & Circles & Archimedes spiral & Spatial spiral \\
\hline & 0.6 & Circles & Archimedes spiral & Spatial spiral \\
\hline \multirow{3}{*}{$37^{\circ}$} & 0.2 & Circles & Archimedes spiral & Spatial spiral \\
\hline & 0.4 & Circles & Archimedes spiral & Spatial spiral \\
\hline & 0.6 & $\begin{array}{c}\text { Circles } \\
\text { CRACKS OCCURENCE }\end{array}$ & Archimedes spiral & Spatial spiral \\
\hline \multirow{3}{*}{$38^{\circ}$} & 0.2 & Circles & Archimedes spiral & Spatial spiral \\
\hline & 0.4 & $\begin{array}{c}\text { Circles } \\
\text { CRACKS OCCURENCE }\end{array}$ & $\begin{array}{c}\text { Archimedes spiral } \\
\text { CRACKS OCCURENCE }\end{array}$ & Spatial spiral \\
\hline & 0.6 & $\begin{array}{c}\text { Circles } \\
\text { CRACKS } \\
\end{array}$ & $\begin{array}{c}\text { Archimedes spiral } \\
\text { CRACKS OCCURENCE }\end{array}$ & Spatial spiral \\
\hline
\end{tabular}

\section{Conclusion}

The main goal of the research presented in this paper was to demonstrate that, if the technological conditions are selected properly, parts made from Ti6Al4V titanium alloy can 
be processed by incremental forming at room temperature. Heating the parts was not considered as an option, in order not the affect the biocompatibility of the parts.

The experimental tests have demonstrated that a slope angle of $38^{\circ}$ is the upper limit for cone-frustum parts machined at room temperature. While this value could be considered small, it is here noticeable that the parts targeted by this research were cranial prostheses, were the slope angles are also small. For these kind of parts, $38^{\circ}$ could be considered as totally acceptable.

Three types of toolpaths were taken into consideration. The best results have been found for the spatial spiral toolpath. The assumption made by the authors was that this toolpath is a continuous one, with only one entry and exit point, a fact which does not favor stress concentrators and consequently does not favor cracks occurrence. Further researches, based by a joint FEM analysis and experimental test process will be performed in order to validate this assumption.

\section{References}

1. A.L. Chicea, R.E. Breaz, 9th International Technology, Education and Development Conference INTED 2015, Madrid, Spain, 3568-3574 (2015)

2. Muresan, G., Morar, L., Breaz, R.E., International Technology, Education and Development Conference Valencia, Spain, 4115-4122 (2014)

3. G. Ambrogio, F. Gagliardi, S. Bruschi, L. Filice, CIRP Annals - Manufacturing Technology, (62/1), 243-246 (2013)

4. G. Palumbo, M. Brandizzi, Materials \& Design (40), 43-51 (2012)

5. G. Ambrogio, L. Filice, F. Gagliardi, Materials \& Design (34), pp. 501-508 (2012)

6. G. Fan, L. Gao, G. Hussain, Z. Wu, International Journal of Machine Tools and Manufacture, (48/15), 1688-1692 (2008)

7. R. Breaz, O. Bologa, M. Tera, G. Racz, The 14th Conference on Metal Forming, Krakow Poland, 427-430 (2012)

8. M. Tera, R.E. Breaz, O. Bologa, G. Racz, Proceedings in Manufacturing Systems, (9/2), 99-104 (2014) 